\title{
Factors Influencing the Discard of Custom-made Garments among Female Students of University of Cape Coast, Cape Coast, Ghana
}

\author{
Olive Asiwome Tsyewu ${ }^{1}$ and Patience Danquah Monnie ${ }^{2}$ \\ ${ }^{1,2}$ Department of Vocational and Technical Education, University of Cape Coast, Cape Coast, Ghana. \\ E-mail:prayfat1@yahoo.com
}

\begin{abstract}
This paper examined the factors that are likely to cause the discard of custom-made garments among female students of the University of Cape Coast. The descriptive survey design was used for the study and the total number of participants was 246. The Predictive Analytical Software was employed for data analyses. The data gathered were analysed using inferential statistics and descriptive statistics such as frequencies and percentages. The study revealed that constructional factors form a higher percentage of the factors that lead respondents to discard their custom-made garments. The major factors that resulted in the discard of custom-made garments among the respondents were poorly stitched garments, poor fit, uncomfortable lining issues, and poor conditions of notions. Slit and Kaba (traditional dress for women in Ghana, the slit is an ankle length skirt and the kaba is a blouse) was the most frequently discarded custom-made garments among the respondents. It was recommended that in decreasing the rate of discard of custom-made garments, dressmakers should select appropriate stitches and notions for garment construction. They should ensure quality in the products they produce and check the fit of the garments properly before handing them over to clients to meet their expectations.
\end{abstract}

Keywords: Custom-made garments; discard; serviceability; female students, clothing.

Citation: Olive Asiwome Tsyewu, Patience Danquah Monnie. Factors Influencing the Discard of Custom-made Garments among Female Students of University of Cape Coast, Cape Coast, Ghana, 2019; 4(1): 65 - 76

Received: January 4, 2019

Accepted: July 5, 2019 
66 One of the possible ways of increasing sustainability within the textiles and clothing industry is to prolong the use period of their products (Cooper, Fisher, Goworek \& Woodward, 2010; Fletcher, 2008). The short life span of products resulting from poor quality issues increases the need for the products to be replaced faster, thus increases the environmental load from production and disposal phases (Laitala \& Klepp, 2011). Kadolph (2007) identified eight common themes of product quality. These include aesthetics, conformance and serviceability. Garment serviceability basically describes the product's ability to meet the consumers' needs, thus the product should meet the intended purpose for which it was constructed (Kadolph, 2007). A garment is considered to be serviceable when it can perform the functions for which it was intended. The serviceability concepts that are used to organise the textile information are aesthetics, durability, comfort and safety, appearance retention, care, environmental impact, and cost. Consumers determine their satisfaction with products based on these serviceability concepts (Kadolph, 2007).

Generally, after a garment has been used for a certain length of time, the garment ceases to be serviceable when it can no longer fulfil its intended purpose in the way that it did when it was new (Kiron, 2013). Users of such garments may then think of how to handle such a garment. In most cases, unserviceable garments may be discarded by the owners. On the other hand, some consumers may decide to repair, alter or remodel the garment to make it fit for use again. However, some products may still not be fit for use after repair, remodelling or alteration and are therefore discarded. In some cases, products may be discarded right after construction without use or an attempt to repair, remodel or alter. Factors that may cause a garment to be unserviceable and lead to discarding include poor fit, outdated style, boredom and/or wear-out (Koch \& Domina, 1999). According to Laitala and Klepp (2011), poor fit, technical quality such as constructional defects and taste-related issues dominate reasons for clothing disposal in addition to situational reasons such as having too many similar garments, lacking closet space and change in body size of the wearer. The need for clothing repair or discard comes from various sources. Poor initial garment workmanship or construction can be a problem with ready-to-wear as well as custommade items. Gracey and Moon (2012) in their report on "Valuing Our Clothes: the evidence base", stipulated that clothes are most commonly unworn because they no longer fit or are in disrepair. This they believed could be attributed to the fact that many people lack an ability to alter clothing or undertake repairs that are more complex. Thus, consumers may discard clothing because of issues related to poor construction such as poor stitching, wrinkles and undesirable garment proportion in relation to the figure of the wearer. These defects that are likely to cause a consumer to dispose off a particular 
garment item may be from the part of the clothing manufacturer.

In Ghana, the production of clothing until recently was mainly custom-made by clothing manufacturers in the informal sector (Fianu \& Zentey, 2000). Chimieloweic (1995) describes the system of production used by Ghanaian clothing producers as non-industrial. Thus they do not follow the general sequential processes in manufacturing garments in the garment industry. According to Fianu and Zentey (2000), majority of Ghanaian clothing companies do not operate under the division of labour system but one person makes the clothing from the beginning to the end thereby resulting in considerable variations in quality and also registering low productivity. Ampofo (2002) concluded that the collapse of the large scale clothing industries in Ghana was due to lack of quality and conformity of standards which may result in the dissatisfaction of their customers with regard to the products they manufacture and therefore likely to lead to frequent clothing disposal. This study was therefore carried out to determine the factors that are likely to cause users of custom-made garments in Ghana to dispose of their garments.

\subsection{Objectives of the Study}

The objectives of the study were to:

1. Determine the custom-made garments disposal habit of female students of the University of Cape Coast, Ghana

2. Ascertain reasons associated with the discard of custom-made garments among female students of the University of Cape Coast, Ghana

3. Find out the duration of use of custom-made garments before discard

4. Find out what respondents do to custom-made garments before discarding

5. Establish if there is an association between the numbers of years of custom-made garments use and discard.

The outcome of the study was anticipated to help highlight the factors that influence the disposal of custom-made garments produced in Ghana, which would contribute to a better understanding of the existing situation and inform stakeholders on what should be considered to enhance the performance of custom-made clothing. The research would, therefore, help in developing a body of knowledge that would assist artisanal dressmakers and other stakeholders in the apparel industry to meet the demands of their clients.

\subsection{Methodology}

The descriptive survey design was used and data was collected at a single point in time.

\subsection{Population}


The research population involved regular undergraduate female students of the University of Cape Coast, Ghana.

\subsection{Sampling Procedure}

Stratified, probability proportional to size (PPS) and simple random sampling techniques were used for the selection of the female students. Stratification was done by distributing the samples into the eight faculties and schools of the University. The simple random sampling (SRS) technique was used for the selection of the respondents where the 'Random Numbers Generator' function in the SPSS (version 20.0) was used. A sample size of 246 was then selected representing the various faculties and schools. This technique ensured that samples selected from each faculty and school fairly represented the total number of female students in that faculty and school.

\subsection{Instruments}

The instrument used for data collection was the questionnaire. The questionnaire was divided into two sections. Section 'A' items sought respondents disposal habit of custom-made garments and reasons associated with discard of garments, 'B' contained responses on the duration of custom-made garments use before discard and what respondents do to custom-made garments before discarding.

\subsection{Data Collection Procedure}

The collection of the data was based on direct contact with respondents. The researchers established rapport with the respondents and explained items that needed to be explained. To easily identify sets of questionnaire for administration and analysis purposes, each set of questionnaire for the various faculties and schools was labelled. For instance, ED for Education students, ART for Arts students and MD for students from the School of Medical Sciences. The participants responded to the questionnaires in their lecture halls in the presence of the researchers. Although the study recorded 100\% retrieval rate, after editing and cleansing, 13 questionnaires were found to be defective (thus some respondents gave multiple answers to questions and others skipped some vital information on the questionnaires) and were removed. This reduced the total number of respondents in the study to 233 representing $94.7 \%$.

\subsection{Data Analysis}

The Predictive Analytical software for windows version 20.0 was employed to aid in the analyses of the data collected. Specifically, the data gathered were analysed using inferential statistics and descriptive statistics such as frequencies and percentages. Results were presented in tables. 


\subsection{Results and Discussion}

The results and discussion are presented based on the objectives of the study. It covers the following thematic areas; respondents' disposal habits of custom-made garments, reasons associated with the discard of custom-made garments, duration of use of custom-made garments before discard, what respondents do to custom-made garments before discarding and finally the association between custom-made garments serviceability and discard.

\subsection{Objectives One and Two: Custom-made Garments Disposal habit and Reasons for Discard}

In Table 1, the disposal habits of participants are presented and Table 2 provides the reasons for custommade garments discard.

Table 1: Most Recent Custom-made Garments Discarded by Respondents

\begin{tabular}{ccc}
\hline Custom-made garments & Frequency & Percentage (\%) \\
\hline Slit and Kaba & 87 & 37.3 \\
Skirt and blouse & 49 & 21.0 \\
Trouser & 38 & 16.3 \\
Blouse & 21 & 9.0 \\
Shirt & 21 & 9.0 \\
Dress & 12 & 5.2 \\
Others & 5 & 2.2 \\
\hline Total & 233 & 100.0 \\
\hline
\end{tabular}

Five common custom-made garment types were outlined and respondents were asked to indicate the most recent type they had discarded and the reason for the discard. Table 1 shows that many (87) respondents had done away with their custom-made slit and kaba, whiles 49 said that they had disposed off their skirt and blouse garments. A substantial number of them 38 also claimed to have recently discarded custommade trousers made for them.

However, of the 87 (37\%) respondents who indicated that slit and kaba was the most recent custom-made 
garment type they had discarded, 49 (56\%) attributed their reasons for discard to constructional factors while the rest $38(44 \%)$ attributed their discard to non-constructional factors. Specifically, 19 (22\%) respondents discarded their slit and kaba because they did not like the fit of the garments just after

construction. Again, 14(16\%) respondents discarded their slit and kaba because stitches used in constructing the garments came off. The remaining nine $(10 \%)$ and seven $(8 \%)$ respondents attributed their discard to poor conditions of notions used on garments and uncomfortable lining conditions respectively (Refer to Table 2).

With regards to custom-made skirts and blouses, out of the 49 (21\%) respondents who reported to have discarded these, $39(80 \%)$ associated their reasons to constructional factors while the rest $10(20 \%)$ respondents associated their discard to non-constructional factors. The specific distributions of these constructional factors are 15 respondents out of the 49 who discarded the skirts and blouses did as a result of poor conditions of notions used on these custom-made garment types. Ten, seven and two respondents ascribed their discard to bad stitches used for garment construction, uncomfortable lining conditions and bad fit just after construction respectively.

Again, from Table 2, of the 233 respondents, 38 (16\%) recently discarded their custom-made trousers. Both constructional and non-constructional factors were reasons enumerated by respondents to have engineered their discard. Here again, of the 38 respondents, 29 representing $76 \%$ of the respondents indicated constructional factors while the nine $(27 \%)$ were non-constructional factors. The implication of these results is that though constructional factors (technical problems) and non-constructional factors (nontechnical problems) influence the decision of custom-made clothing discard, constructional factors form a higher percentage of the reasons given by respondents to have led to the discard of their custom-made garments.

This finding confirms results in a similar work carried out by Laitala and Klepp (2011) where technical problems (constructional factors) which results in quality related issues were the most common reasons given for clothing disposal even though a large amount of clothing was also discarded because of situational reasons (new fashion trends, change in body size, wear and tear). 
Table 2: Crosstabulation between Custom-made Garments Discarded and Reasons for their Discard

\begin{tabular}{|c|c|c|c|c|c|c|c|c|c|c|}
\hline \multicolumn{11}{|c|}{ Reasons for the discard of custom-made garment } \\
\hline Types of dress & CBS & CAW & GWO & BS & PCN & UL & $\mathrm{BF}$ & $\mathrm{OV}$ & TU & TOTAL \\
\hline \multirow[t]{2}{*}{ Slit \& Kaba } & 20 & 4 & 4 & 14 & 9 & 7 & 19 & 3 & 7 & 87 \\
\hline & $(23.0)$ & $(4.6)$ & $(4.6)$ & $(16.1)$ & $(10.3)$ & $(8.0)$ & $(21.8)$ & $(3.4)$ & $(8.0)$ & $(100.0)$ \\
\hline \multirow[t]{2}{*}{ Skirt \& blouse } & 7 & 2 & 1 & 10 & 15 & 7 & 2 & 0 & 2 & 49 \\
\hline & $(14.3)$ & $(4.1)$ & $(2.0)$ & $(20.4)$ & $(30.6)$ & (14.3) & (4.1) & $(0.0)$ & $(4.1)$ & (100.0) \\
\hline \multirow[t]{2}{*}{ Blouse only } & 3 & 2 & 1 & 5 & 6 & 0 & 4 & 0 & 0 & 21 \\
\hline & (14.3) & (9.5) & $(4.8)$ & $(23.8)$ & (28.6) & $(0.0)$ & $(19.0)$ & $(0.0)$ & $(0.0)$ & (100.0) \\
\hline \multirow[t]{2}{*}{ Shirt only } & 3 & 1 & 3 & 6 & 4 & 0 & 3 & 0 & 1 & 21 \\
\hline & $(14.3)$ & $(4.8)$ & $(14.3)$ & $(28.6)$ & $(19.0)$ & $(0.0)$ & $(14.3)$ & $(0.0)$ & $(4.8)$ & $(100.0)$ \\
\hline
\end{tabular}

Key: CBS-Change in Body Size; CAW- Change after Washing; GWO-Garment was Worn out; BS-Bad Stitches; PCN - Poor Condition of Notions; UL-Uncomfortable Underlining; BF- Bad Fit; OV - Out of Vogue; and TU-Tired of Garments. 
Reasons for the discard of custom-made garment

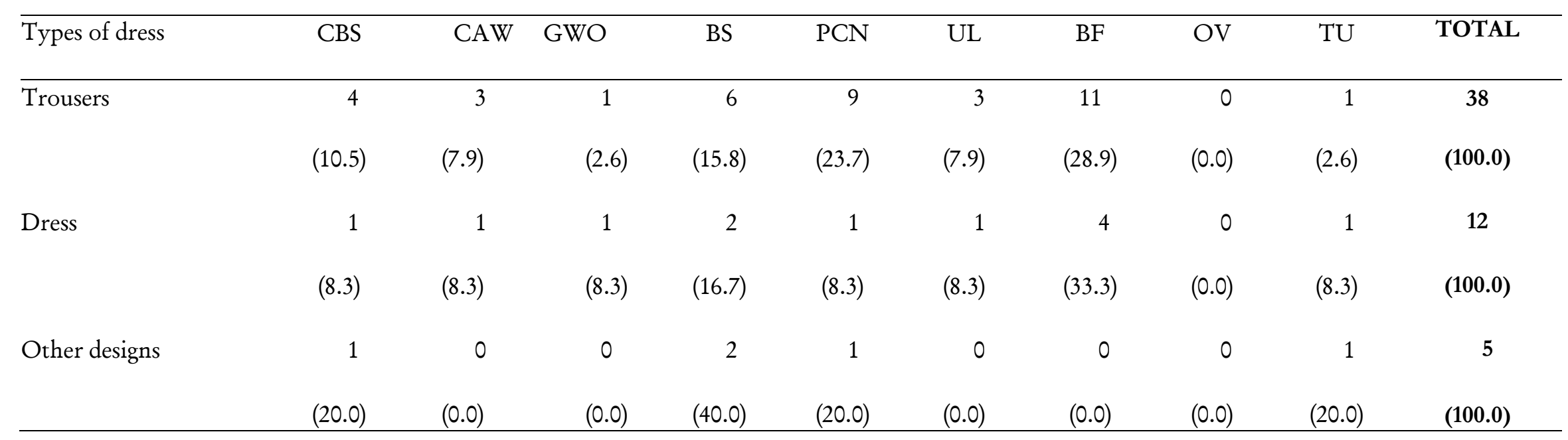

Key: CBS-Change in Body Size; CAW- Change after Washing; GWO-Garment was Worn out; BS- Bad Stitches; PCN - Poor Condition of Notions; UL-Uncomfortable Underlining; BF- Bad Fit; OV-Out of Vogue; and TU-Tired of Garments. 
3.2 Objectives Three and Four: Duration of Custom-made garments use before discard and what is done to custom-made garments before discard

The duration within which custom-made garments are used before discarded was also investigated. Respondents were asked to indicate the number of years they used their custom-made garments before discarding them. Table 3 provides a summary of the duration of use of custom-made garments by the respondents.

Table 3: Duration of use of custom-made garments before discarding

\begin{tabular}{|c|c|c|c|c|c|c|c|c|}
\hline \multirow[b]{2}{*}{ Garment Type } & \multicolumn{2}{|c|}{ Did not wear } & \multicolumn{2}{|c|}{$1-2$ years } & \multicolumn{2}{|c|}{ 3-4 years } & \multicolumn{2}{|c|}{5 years or more } \\
\hline & No. & $\%$ & No. & $\%$ & No. & $\%$ & No. & $\%$ \\
\hline Slit and Kaba & 48 & 20.6 & 92 & 39.4 & 57 & 24.5 & 36 & 15.5 \\
\hline Skirt and blouse & 40 & 17.2 & 107 & 45.9 & 70 & 30.0 & 16 & 6.9 \\
\hline Blouse only & 51 & 21.9 & 92 & 39.5 & 73 & 31.3 & 17 & 7.3 \\
\hline Shirt only & 48 & 20.6 & 105 & 45.1 & 69 & 29.6 & 11 & 4.7 \\
\hline Trousers & 55 & 23.6 & 88 & 37.8 & 65 & 27.9 & 25 & 10.7 \\
\hline Dress & 55 & 23.6 & 89 & 38.2 & 51 & 21.9 & 38 & 16.3 \\
\hline
\end{tabular}

Multiple Responses

The results from Table 3 show that 40\% of slit and kaba users had used the garment for at least three years, while 37\% who used skirt and blouse, $39 \%$ of blouse users and $34 \%$ of shirt users said that they discarded the garments after three years. As much as $38 \%$ each of trousers and dress users 
discarded them between 1-2 years. Interestingly none of the respondents indicated that they had discarded a custom-made garment within a year of usage.

To find out whether respondents tried to put custom-made garments back to use after they became unserviceable, respondents were requested to indicate what they do to their garments before discarding the garments. The results showed that, of the total number of respondents, about $41 \%$ said they discarded their custom-made garment outright when they realized they were not in good condition. Twenty-five percent changed their styles, 19.3\% repaired/mended their garments and $16 \%$ renovated their custom-made garments.

\subsection{Objective Five: Association between years of garment use and discard}

Chi-square test was carried out to determine the association between years of garment use and discard and the results are presented in Tables 4 and 5.

Table 4: Crosstabulation between Years of garment use and discard

\begin{tabular}{lccccc}
\hline \multicolumn{6}{c}{ Range of Serviceability } \\
\hline Years of Discard & $1-5$ & $6-10$ & $11-15$ & 16 and above & Total \\
\hline $1-5$ & 0 & 0 & 0 & 0 & 0 \\
$6-10$ & 2 & 13 & 21 & 3 & 39 \\
$11-15$ & 4 & 49 & 76 & 5 & 134 \\
16 and above & 0 & 17 & 41 & 2 & 60 \\
\hline Total & $\mathbf{6}$ & $\mathbf{7 9}$ & $\mathbf{1 3 8}$ & $\mathbf{1 0}$ & $\mathbf{2 3 3}$ \\
\hline
\end{tabular}

Table 5: Chi-square Test Results on the association between numbers of years of garment use and discard

Years of use

\begin{tabular}{|c|c|c|}
\hline \multirow[t]{3}{*}{ Discard } & Chi-square value & 5.904 \\
\hline & $p$ (2-tailed) & 0.434 \\
\hline & Df & 6 \\
\hline
\end{tabular}


The results in Tables 4 and 5 indicate that there was no significant association between the numbers of years of custom-made garment use and discard. This is because the $p$-value of 0.434 is greater than the significance level of 0.05 . The implication is that other reasons other than the duration of use of cloths might be responsible for the respondents' discard of custom-made garments. As noted in this study, the major reasons for custom-made garment discard are technical issues such as wrong stitching and poor fit.

\subsection{Conclusion}

Based on the findings from the study, it can be concluded that though constructional factors (technical problems) and non-constructional factors (non-technical problems) contribute to custom-made garments discard, constructional factors form a higher percentage of the factors. The major factors that resulted in the discard of custom-made garments among the respondents were poorly stitched garments, poor fit, uncomfortable lining issues, and poor conditions of notions. Although some respondents try to put their garments back into shape by mending, custom-made garments are discarded regardless of the number of years it has been used. Some people even discard their garments even without wearing them with slit and kaba being the most frequently discarded custom-made garment.

\subsection{Recommendations}

The following recommendations are made based on the results of the study. In decreasing the rate of discard of custom-made garments (especially slit and kaba) among females, dressmakers should select appropriate stitches and notions for garment construction. They should ensure quality in the products they produce and check the fit of the garments properly before handing them over to clients to meet their expectations. The fit level can be ascertained when the garment is ready so that any ill-fit can be corrected as early as possible. This is because customers will abruptly stop using a garment which has a poor fit. It is suggested that further studies are conducted on the issues of clothing discard such as on ready sewn garments to provide a broader picture of the factors influencing clothing discard among consumers. 


\section{References}

1. Chimieloweic, R. (1995). Rehabilitation of the Textiles and Garment Industry. SI/GHA/94/802-Advisory mission Technical Report, post-11-52. Unpublished Draft Reports The Ghana Government by UNIDO acting Executive Agency for UNDP.

2. Cooper, T., Fisher, T., Hiller, A., Goworek, H. and Woodward, S. (2010) Excessive speed / Short lives: Attitudes to clothing longevity and disposal Sustainability in Design: NOW! Challenges and Opportunities for Design Research, Education and Practice in the XXI Century, LENS (Learning Network on Sustainability) conference, Bangalore, India, 29 September-1 October.

3. Fletcher, K. (2008). Sustainable fashion and textiles. London, UK: Earthscan.

4. Fianu, A. G., \& Zentey, E. A. (2000). Problems of Large-scale Fashion Designers in Accra, Ghana. Journal of Consumer Studies \& Home Economics, Vol 24, No 2, pp 128-136.

5. Gracey F., \& Moon, D. (20012). Valuing our clothes: the evidence base. WRAP, Material change for a better environment.

6. Kiron, M. I. (2013). What is serviceability? Factors of serviceability. Retrieved November 5, 2015, from http://www.ehow.com/how_7168071_manage-quality-apparel-industry- servicability.html

7. Laitala1, K., \& Klepp, I. G. 2011). Environmental improvement by prolonging clothing use period. Towards sustainability in the Textile and Fashion industry, Copenhagen 26-27

8. Ampofo, V. O. (2002). Ghana's Textiles/Garment Industry. Industrial Development and Investment Division (Ministry of Trade and industry-Ghana). Retrieved 20 September 2015, fromhttp://www.intracen.org/worldtradenet/docs/whatsnew/atc_lesotho_november2000/country_ paper_ghana.pdf

9. Kadolph, J. S. (2007). Quality assurance for textiles and apparel ( $2^{\text {nd }}$ ed.). New York: Fairchild Publications.

10. Koch, K., \& Domina, T. (1999). Consumer textile recycling as a means of solid waste reduction. Family and Consumer Sciences Research Journal, Vol 28, pp 3-17. 